\title{
Article \\ Analysis of Climate Change Effects on Surface Temperature in Central-Italy Lakes Using Satellite Data Time-Series
}

\author{
Davide De Santis* (D), Fabio Del Frate and Giovanni Schiavon
}

Citation: De Santis, D.; Del Frate, F.; Schiavon, G. Analysis of Climate Change Effects on Surface Temperature in Central-Italy Lakes Using Satellite Data Time-Series. Remote Sens. 2022, 14, 117. https:// doi.org/10.3390/rs14010117

Academic Editors: Arun Mondal and Pavel Kishcha

Received: 30 November 2021 Accepted: 23 December 2021 Published: 28 December 2021

Publisher's Note: MDPI stays neutral with regard to jurisdictional claims in published maps and institutional affiliations.

Copyright: (C) 2021 by the authors. Licensee MDPI, Basel, Switzerland. This article is an open access article distributed under the terms and conditions of the Creative Commons Attribution (CC BY) license (https:// creativecommons.org/licenses/by/ $4.0 /)$.
Department of Civil Engineering and Computer Science Engineering, "Tor Vergata" University of Rome, 00133 Rome, Italy; fabio.del.frate@uniroma2.it (F.D.F.); schiavon@uniroma2.it (G.S.)

* Correspondence: davide.de.santis@uniroma2.it

\begin{abstract}
Evaluation of the impact of climate change on water bodies has been one of the most discussed open issues of recent years. The exploitation of satellite data for the monitoring of water surface temperatures, combined with ground measurements where available, has already been shown in several previous studies, but these studies mainly focused on large lakes around the world. In this work the water surface temperature characterization during the last few decades of two small-medium Italian lakes, Lake Bracciano and Lake Martignano, using satellite data is addressed. The study also takes advantage of the last space-borne platforms, such as Sentinel-3. Long time series of clear sky conditions and atmospherically calibrated (using a simplified Planck's Law-based algorithm) images were processed in order to derive the lakes surface temperature trends from 1984 to 2019. The results show an overall increase in water surface temperatures which is more evident on the smallest and shallowest of the two test sites. In particular, it was observed that, since the year 2000, the surface temperature of both lakes has risen by about $0.106{ }^{\circ} \mathrm{C} /$ year on average, which doubles the rate that can be retrieved by considering the whole period $1984-2019\left(0.053{ }^{\circ} \mathrm{C} /\right.$ year on average).
\end{abstract}

Keywords: climate change; temperature; lakes; water resources; satellite; Landsat; time-series; Sentinel-3

\section{Introduction}

Nowadays we are facing an era of climate change, and rising temperatures are affecting all terrestrial ecosystems. In this context lake and inland water temperatures are also increasing regularly all over the world, leading to high risks for all species. This phenomenon triggers consequences such as abnormal frequency of algal bloom occurrence, in particular the harmful ones which put the entire lake ecosystem in danger, and an increase of water loss through evaporation [1,2]. The climate is changing rapidly [3], and lakes are warming with correlated velocity on a global scale and in several regions with different climatic characteristics [4-10]. The direct or indirect effects of global warming on lake ecosystems has been analyzed in several recent studies [11-13]. New research also pointed out that lake heatwaves are becoming more frequent over the years [14]. However, most of the literature regarding the impact of climate change on lakes only considers wide water bodies (order of hundreds of $\mathrm{km}^{2}$ ) due to the larger availability of historical data with respect to smaller ones.

Water surface temperature (WST) is a key parameter for analysing the impact of climate change on lake ecosystems. WST can be obtained by processing satellite data with thermal sensors that acquire information within the thermal infrared (TIR) window of the electromagnetic spectrum. These data are becoming an important source of integration for the ground-based measurement network and even the main source of data when a ground network of sensors is absent. On the other hand, WST values retrieved by satellite data allow us to fill in the spatial and temporal gap that affects in situ measurements at ground level in most of the cases regarding small-medium lakes. 
In fact, during the current climate change era, the ecosystem of inland waters has been particularly impacted by drought and rising temperatures, leading to stress conditions for native flora and fauna species. In most of cases there is not a proper network of ground sensors for monitoring the water temperatures of small-medium lakes, and satellite data can play a key role in filling this deficiency. In particular, due to the absence of in situ data, it may be complex to properly evaluate the long-term water temperature trend by means of models. To solve this problem, we can use the huge source of information provided by satellites and, in particular, the Landsat program, which so far has collected about 40 years of continuous data. Thanks to its moderate spatial resolution ranging from 60 to $120 \mathrm{~m}$ in the thermal infrared window, the processing of Landsat imagery even allows for the registration of the water surface temperature evolution of small lakes.

Several studies have focused on lake water surface temperature estimation, in particular of large lakes, using satellite data, e.g., ATSR and AVHRR series [15] and MODIS [16,17]. However, despite the research available on lake water monitoring in the last few decades, there are some limitations due to the fusion of multiple satellite sources. Often all summer months are considered, and most of the methodologies and data cannot be used for lakes with smaller extensions. Usually, in this latter case, a proper in situ measurement network is not even available. Additional issues affecting other research (e.g., [18]) are the non-synchronous acquisition of different satellite platforms, the variable spatial resolution and the difficulty of achieving perfect synchronicity of registration between satellite data and lake WST from ground-based sensors.

Given this background, the main objectives of our study are the following:

- $\quad$ to develop an algorithm to retrieve water surface temperatures for small-medium size lakes with surfaces larger than $0.05 \mathrm{~km} \times 0.05 \mathrm{~km}$ exploiting the Landsat program, in particular Landsat-5, Landsat-7 and Landsat-8 missions, from 2000 to 2019 and define a robust validation analysis;

- $\quad$ to implement a methodology for extracting temperature information from Landsat data acquired before 2000 since no atmospheric correction procedure is available using the NASA tool (which will be presented in Section 3.1);

- to apply the proposed methodology to both Lake Bracciano and Lake Martignano, among the most important lakes in Central Italy, in order to evaluate water surface temperature trends during the period 1984-1999;

- $\quad$ to compare the water surface temperature trends discovered from the last 20 years with those from the last 35 years.

\section{Study Sites}

Lake Bracciano (42.12 N, 12.23 E) and Lake Martignano (42.113 N, 12.315 E) are two volcanic lakes located $30 \mathrm{~km}$ northwest of Rome (Italy) [19] belonging to the Sabatini Volcanic District (Figure 1). Lake Bracciano is an important fresh-water reservoir in the center of Italy, and for a long time its water has been used as a supply for a part of the Rome metropolitan area. According to the last published management plant, Lake Bracciano does not have a suitable network to monitor some of the most important parameters, such as the water temperature [20]. The lake has a surface area of 57.5 square kilometers, a maximum depth of $160 \mathrm{~m}$ and a volume of 4.95 cubic kilometers.

Table 1. Morphometric characteristics of the two volcanic lakes considered in this study [21].

\begin{tabular}{ccccc}
\hline Lake & $\begin{array}{c}\text { Area } \\
\left(\mathbf{k m}^{\mathbf{2}}\right)\end{array}$ & $\begin{array}{c}\text { Volume } \\
\left(\mathbf{k m}^{\mathbf{3}}\right)\end{array}$ & $\begin{array}{c}\text { Max Depth } \\
\mathbf{( m )}\end{array}$ & $\begin{array}{c}\text { Altitude } \\
(\mathbf{m} \text { a.s.1.) }\end{array}$ \\
\hline Bracciano & 57.5 & 4.95 & 160 & 164 \\
Martignano & 2.5 & 0.0712 & 54 & 207 \\
\hline
\end{tabular}




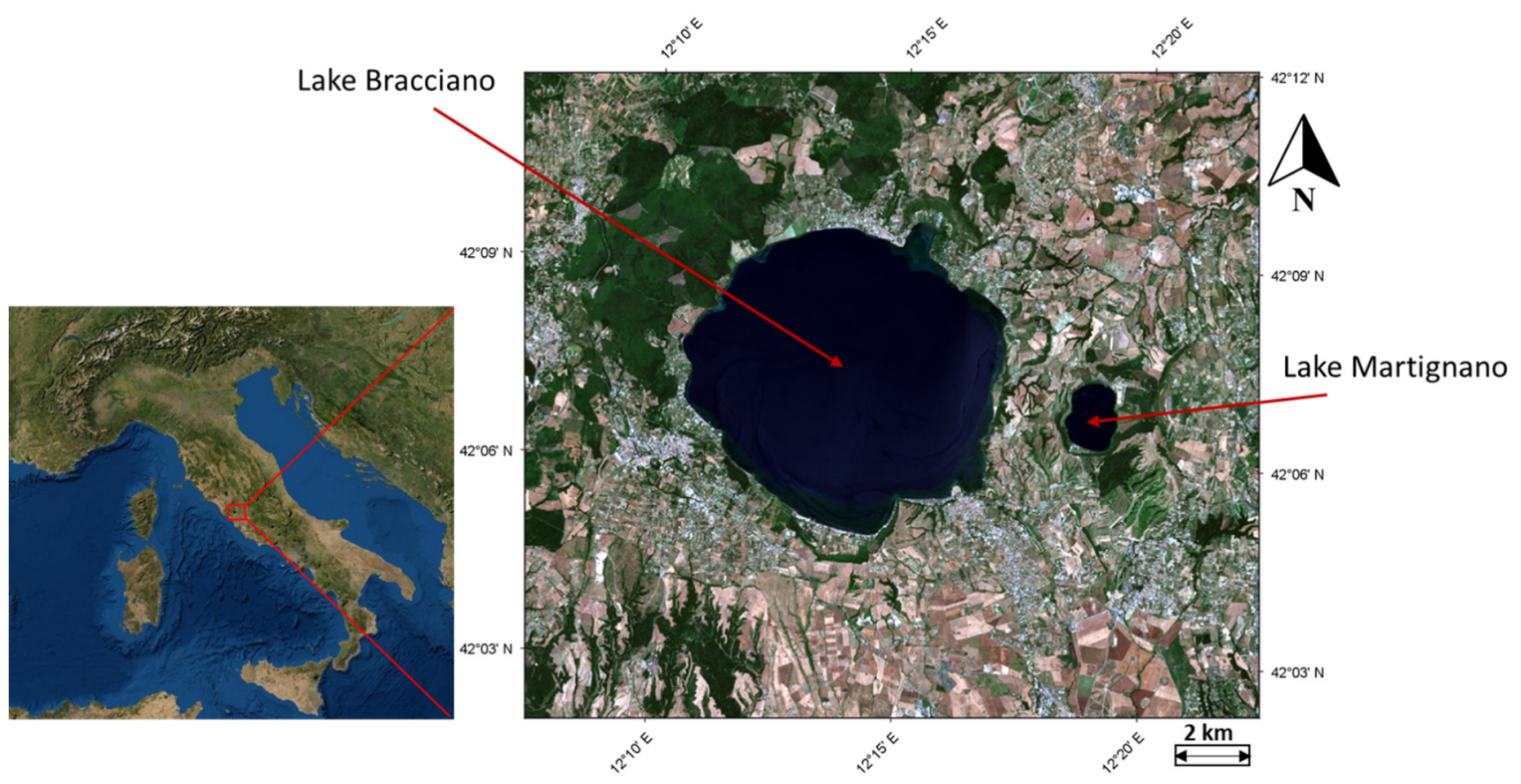

Figure 1. The Lakes of Bracciano and Martignano, natural RGB composite from Sentinel-2 L2A product acquired on 30 June 2019.

Lake Bracciano is a rich source of flora and fauna, including the endemic algae Isoëtes Sabatina—as far as we know, not to be found anywhere else [22]—and plentiful stocks of fish.

As with every deep lake, Lake Bracciano is characterized by a great thermal stratification stability in the event of an increase in the water temperature. This phenomenon causes a decrease in the depth of the mixing layer and, consequently, a higher risk of eutrophication, with algal and cyanobacterial blooms, leading to poorer water quality [23].

Close to Bracciano there is a second smaller lake called Lake Martignano for which we assumed the same approach to obtain the water surface temperature. The main morphometric characteristics of these lakes are reported in Table 1. The Lakes of Bracciano and Martignano have no affluents, while Bracciano has an effluent with a non-significant flow for greater part of the year; therefore, both lakes can be considered as isolated water basins affected by weather conditions and climate change.

In this work we retrieved a multi-decadal thermal characterization of the two water bodies which have different morphological features but belong to the same climatic zone. Then we analysed the water surface temperature trend in order to derive a quantitative assessment of the different global warming impact on the water surface temperature of the two lakes.

\section{Materials and Methods}

We defined a proper mask for both Lake Bracciano and Lake Martignano to only take into account water pixels in the Landsat data processed. We always considered the borders of our regions of interest to be at least $200 \mathrm{~m}$ away from the coast in order to exclude mixed pixels from the image. A total of 55,296 water pixels were considered for the analysis of Lake Bracciano and 1295 water pixels represent Lake Martignano.

We assumed the same climatic zone features and boundary conditions for both lakes in the algorithm application, since their centroids are just $7 \mathrm{~km}$ apart.

\subsection{Lakes Surface Temperature Characterization from 2000 to 2019}

We considered all the Landsat-5 TM, Landsa-7 ETM+ and Landsat-8 TIRS data acquired over the test sites, with path 191 and row 31, from 2000 to 2019 (see Table 2 for 
details). A total of 316 Level-1 Precision and Terrain Corrected Product (L1TP) images were considered. The USGS EROS archive freely provides all the Landsat images that are available for downloading on the EarthExplorer website (https:/ / earthexplorer.usgs.gov/, accessed on 8 March 2021).

Table 2. Summary of characteristics of the dataset (2000-2019) created for the scope of the work.

\begin{tabular}{ccccc}
\hline Satellite & N. of Images & Period & Band & \multicolumn{2}{c}{$\begin{array}{c}\text { Spectral Range } \\
(\boldsymbol{\mu m})\end{array}$} & $\begin{array}{c}\text { Spatial Resolution (m) } \\
\text { Landsat-5/TM }\end{array}$ & 63 & $2000-2011$ & B6 & $10.4-12.5$ \\
Landsat-7/ETM+ & 178 & $2000-2019$ & B6 & $10.4-12.5$ \\
Landsat-8/TIRS & 75 & $2013-2019$ & B10 & $10.6-11.2$ \\
\hline
\end{tabular}

Located in the middle of the scenes, our study area was not affected by ETM+ SLC-off error bands, and thus, we were also able to use Landsat-7 data acquired after 2003, usually not easy to work with because of the error stripes covering most of the image.

For the water temperature retrieval, we used a radiative transfer equation-based method already tested in previous studies (e.g., [18]), which considers the effects of the atmosphere on the spectral radiance registered by the sensor.

We based our analysis on the three following hypotheses:

- for the Landsat radiance within the TIR window, the only atmospheric noise is the water vapor absorbance - the effect of the aerosol interaction with spectral radiance measured is ignored;

- only Landsat imagery with clear sky conditions over the study area were selected and processed (i.e., we considered only data with no clouds above the study sites);

- the water temperature trends for the water bodies have to be referenced to the acquisition time of the Landsat satellites over the test case area which is almost the same for all data processed (around 10:00 UTC).

To select which satellite acquisition was suitable for our workflow, we checked the cloud cover presence over the study sites by visual inspection and we rejected some of the Landsat data from the initial dataset. In the event of cloud coverage, in fact, temperature values cannot be calculated since water vapor absorption degrades the spectral radiance measured by the sensor. In a significant portion (197 products) of the initial dataset considered, there was a clear sky condition over both the water bodies and the WST was calculated for each pixel within the polygon of the basin, excluding pixels with a distance less than $200 \mathrm{~m}$ from the boundaries to avoid soil temperature contamination in the results as explained before.

A simplified approach based on the Planck equation for computing water temperature from Landsat single TIR band represents an efficient option for computing lake surface temperature with good accuracy. In the following parts of the article, this approach will be called "method 1". From the electromagnetic energy registered in the thermal infrared window, the water surface temperature has been obtained through a radiative transfer equation-based algorithm [18,24], according to the following workflow. The first step is the radiometric calibration, where the spectral radiances are obtained from the digital number values measured by sensors onboard satellites (Equation (1)).

$$
L_{1}=\left(\frac{L_{\max } \lambda-L_{\min \lambda}}{D N_{\max }-D N_{\min }}\right) \times\left(D N-D N_{\min }\right)+L_{\min \lambda}\left[\frac{\mathrm{W}}{\mathrm{m}^{2} \cdot \mathrm{sr} \cdot \mu \mathrm{m}}\right]
$$

$L_{1}$ is the spectral radiance, $D N$ is the digital number, $D N_{\min }$ is the minimum pixel value before radiometric calibration (fixed $D N_{\min }=0$ ), $D N_{\max }$ is maximum pixel value before radiometric calibration, and $L_{\min \lambda}$ and $L_{\max \lambda}$ are the spectral radiances scaled on the base of $D N_{\min }, D N_{\max }$ and they are provided in Landsat satellites product metadata. 
The second step is the atmospheric calibration to retrieve the spectral radiance values atmospherically corrected. This phase is crucial in computing surface temperatures from satellite data because of the strong absorption within thermal channels in the event of a high concentration of water vapor in the air column affecting the spectral radiance measured by the sensor in the thermal infrared range.

For the atmospheric calibration (Equation (2)), we used three atmospheric parameters derived from the web tool for Landsat data thermal bands correction developed by NASA and available at the link http:/ / atmcorr.gsfc.nasa.gov (accessed on 7 May 2021). For a given position, date, time and a specific Landsat thermal band, the parameter calculator computes the corresponding atmospheric upwelling $(L \uparrow)$ and downwelling $(L \downarrow)$ radiance and the total atmospheric transmission $(\tau)$ between the surface and the sensor $[25,26]$.

$$
L_{2}=\left(\frac{L_{1}-L \uparrow}{\varepsilon \cdot \tau}\right)-\left(\frac{1-\varepsilon}{\varepsilon}\right) \times L \downarrow \quad\left[\frac{\mathrm{W}}{\mathrm{m}^{2} \cdot \mathrm{sr} \cdot \mu \mathrm{m}}\right]
$$

where $L_{2}$ is the spectral radiance atmospherically corrected and $\varepsilon$ is the surface spectral emissivity, which for freshwater lakes can be assumed a value of 0.98 [27]. Anyway, using this approach for data atmospheric calibration, there is an intrinsic limit of the web tool for which atmospheric profiles older than January 2000 are not available. Thus, it is not possible to estimate atmospheric corrected spectral radiance for Landsat data acquired before 2000 and, consequently, retrieve accurate surface temperature values with the same algorithm implemented for products collected from 2000 to 2019.

In the last step, the atmospherically corrected water surface temperature is obtained (Equation (3)) by inverting the Planck's function with the $K_{1}$ and $K_{2}$ conversion constants, respectively, defined for each Landsat sensor and reported among metadata (see Table 3).

$$
W S T=\left(\frac{K_{2}}{\ln \left(\frac{K_{1}}{L_{2}}+1\right)}\right)[K]
$$

Table 3. $K_{1}$ and $K_{2}$ conversion constant for each Landsat platform.

\begin{tabular}{ccc}
\hline Satellite & $\boldsymbol{K}_{\mathbf{1}}$ & $\boldsymbol{K}_{\mathbf{2}}$ \\
\hline Landsat-5/TM & 607.76 & 1260.56 \\
Landsat-7/ETM+ & 666.09 & 1282.71 \\
Landsat-8/TIRS & 774.885 & 1321.079 \\
\hline
\end{tabular}

\subsection{Lakes Surface Temperature Characterization from 1984 to 2019}

Landsat data are available from 1984 and we should consider a temporal window as wide as possible to provide a robust assessment of climate change effects over an ecosystem. On the other hand, the aforementioned NASA tool does not provide parameters for atmospheric correction of Landsat products acquired before 2000.

We propose a linear regression-based method for extending the lake WST analysis back in time to 1984 by changing Equation (2) of the aforementioned "method 1". In particular, the $L_{2}$ parameter of Equation (2) was estimated from $L_{1}$ using a linear regression. For each Landsat platform, Figure 2 shows the scatterplot between the spectral radiance measured at the top of atmosphere (TOA) and at the bottom (BOA), respectively. 

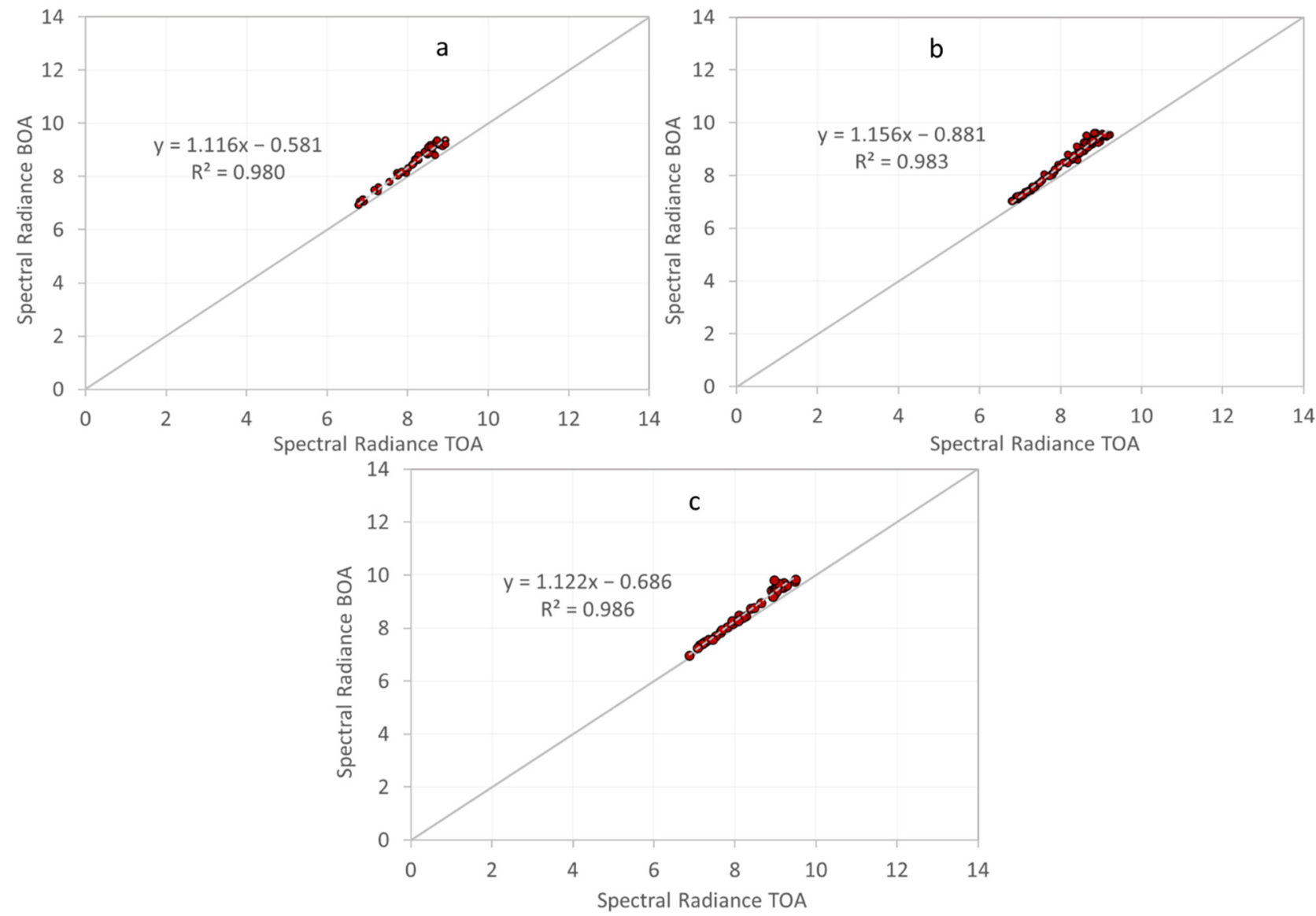

Figure 2. Linear regression between spectral radiance BOA and TOA for Landsat-5 (a), Landsat-7 (b) and Landsat-8 data (c).

Once we checked the significant linear correlation between the two variables, we derived the corresponding equation for estimating the spectral radiance BOA without the use of the NASA tool for retrieving the atmospheric correction parameters needed in "method 1" shown in Section 3.1. In the rest of the article, the approach we propose in this section will be called "method 2". A sum of 172 Landsat-5 TM and 5 Landsa-7 ETM+ Level1 Precision and Terrain Corrected Product (L1TP) products acquired over the considered study from 1984 to 1999 and freely available at https:/ / earthexplorer.usgs.gov / (accessed on 7 May 2021) was added to the dataset described in the previous section (Table 2). Table 4 shows the summary of the additional Landsat products collected.

Table 4. Summary of the characteristics of the additional dataset (1984-1999) created for the scope of the work.

\begin{tabular}{cccccc}
\hline Satellite & N. of Images & Period & Band & $\begin{array}{c}\text { Spectral Range } \\
(\mu \mathrm{m})\end{array}$ & Spatial Resolution $(\mathrm{m})$ \\
\hline Landsat-5/TM & 167 & $1984-1999$ & B6 & $10.4-12.5$ & 120 \\
Landsat-7/ETM+ & 5 & 1999 & B6 & $10.4-12.5$ & 60 \\
\hline
\end{tabular}

\section{Lakes Surface Temperature Results}

\subsection{Lakes Surface Temperature Characterization from 2000 to 2019}

From the initial dataset we selected 197 images with clear sky conditions for both lakes by visual inspection. By averaging all the pixel values corresponding to each region of interest in both Lake Bracciano and Lake Martignano, we estimated the corresponding water surface temperature using the aforementioned procedure. 
Furthermore, in order to derive the average temperature associated with each month, we grouped all the satellite products acquired during the same month and then computed the mean, deriving 140 monthly averaged WST estimates. In Figure 3 the monthly averaged WST evolution using "method 1" from 2000 to 2019 for both lakes is reported. From the trend lines it can be seen that the slope factor associated to the WST values temporal evolution for Lake Martignano (light blue) is higher than that of Bracciano (red).

The water temperature mean value for each month and the corresponding information about the standard deviation and number of measurements are shown in Table 5.

Table 5. Average year derived from Lansdat data acquired from 2000 to 2019 using a standard WST algorithm.

\begin{tabular}{cccccc}
\hline Month & $\begin{array}{c}\text { Mean T } \\
\text { Bracciano } \\
\left({ }^{\circ} \mathbf{C}\right)\end{array}$ & $\begin{array}{c}\text { St.D } \\
\text { Bracciano } \\
\left({ }^{\circ} \mathbf{C}\right)\end{array}$ & $\begin{array}{c}\text { Mean T } \\
\text { Martignano } \\
\left({ }^{\circ} \mathbf{C}\right)\end{array}$ & $\begin{array}{c}\text { St.D } \\
\text { Martignano } \\
\left({ }^{\circ} \mathbf{C}\right)\end{array}$ & $\begin{array}{c}\text { N. of } \\
\text { Measures }\end{array}$ \\
\hline January & 10.12 & 0.99 & 8.61 & 1.11 & 8 \\
February & 9.12 & 0.63 & 7.75 & 0.94 & 12 \\
March & 10.4 & 1.02 & 10.05 & 1.43 & 14 \\
April & 15.3 & 1.81 & 16.11 & 1.78 & 12 \\
May & 20 & 2.33 & 20.71 & 1.86 & 10 \\
June & 25.04 & 2.35 & 25.77 & 2.28 & 15 \\
July & 26.39 & 0.96 & 27.28 & 1.01 & 18 \\
August & 26.5 & 1.14 & 27.16 & 1.1 & 16 \\
September & 23.4 & 1.89 & 23.54 & 1.98 & 9 \\
October & 20.04 & 1.69 & 19.74 & 1.94 & 10 \\
November & 16.15 & 1.23 & 15.1 & 1.29 & 8 \\
December & 12.94 & 0.73 & 11.66 & 0.74 & 8 \\
\hline Average & 17.95 & 1.4 & 17.79 & 1.45 & \\
\hline
\end{tabular}

We noted that for both lakes the minimum water temperature values were registered in February while the maximum ones were obtained in August for Lake Bracciano and in July for Lake Martignano. As we expected, during the summer we collected more exploitable Landsat images than in other seasons. In particular, our averaged WST values were retrieved from at least 15 satellite images acquired in June, July and August and, on the other hand, only eight clear sky Landsat products were available for February, November and December.

From the scatter plot in Figure 4 , an overall consistency $\left(R^{2}\right.$ is higher than 0.99$)$ between the temperature values of the two lakes obtained from each processed Landsat product can be seen. Furthermore, it can be better observed how, for each year of the considered period, the highest and lowest temperatures are typically associated with Lake Martignano's surface. 


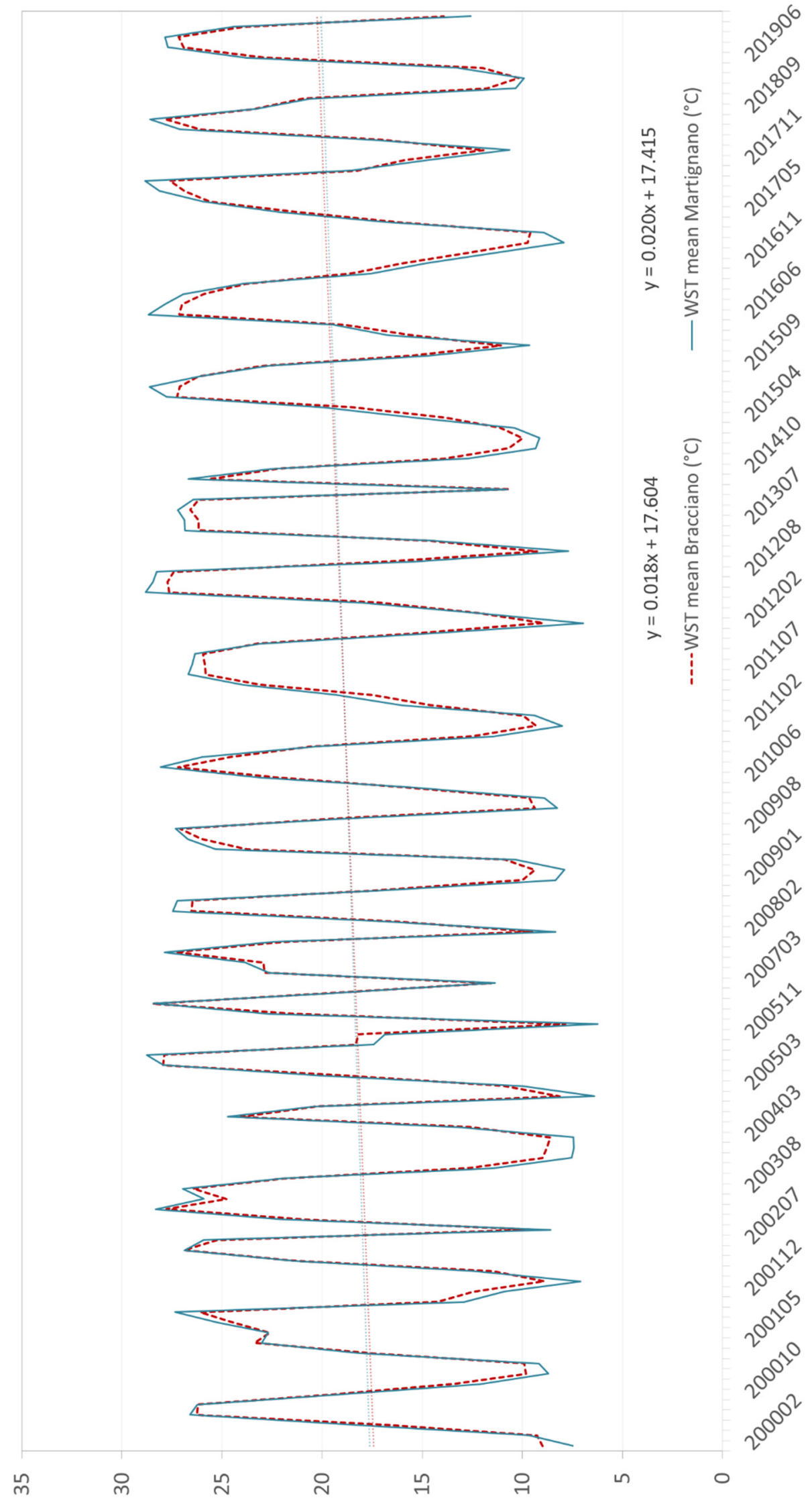

Figure 3. Monthly averaged WST derived from Landsat products with "method 1" from 2000 to 2019 for Lake Bracciano (red) and Lake Martignano (light blue). 


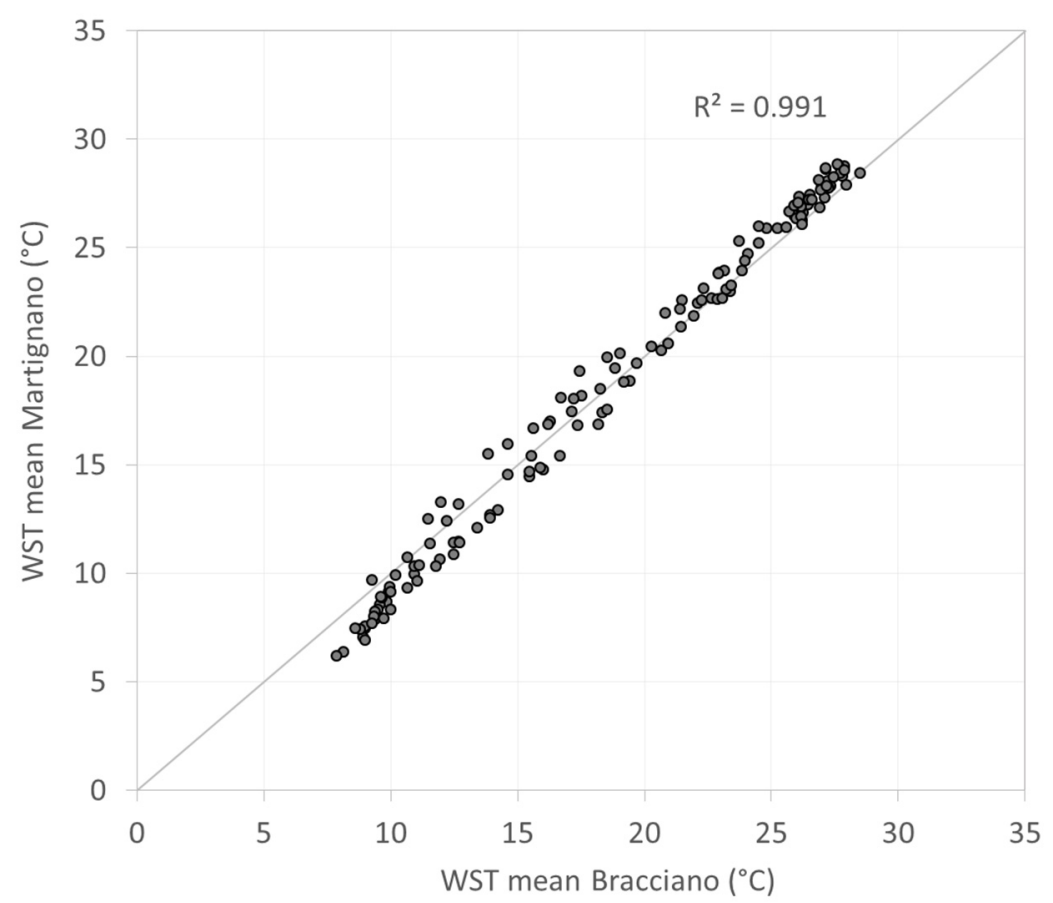

Figure 4. Scatter plot for comparing water surface temperatures derived from Landsat products from 2000 to 2019 for Lake Bracciano (horizontal axis) and Lake Martignano (vertical axis).

\subsection{Lakes Surface Temperature Characterization from 1984 to 2019}

We derived an additional 119 images from between 1984 and 1999 without cloud coverage over the study sites through visual analysis. When two acquisitions were available for the same month, a mean was computed and, at the end, we added 91 monthly water surface temperatures to the previous set for both lakes. Overall, a sum of 230 monthly averaged WST values from 1984 to 2019 were computed using "method 2". The total clear sky dataset available for our test cases derived from multiple Landsat platforms is reported in Figure 5. We grouped all the satellite products by month of acquisition and then we obtained the average values per month that are shown in Table 6.

Table 6. Average year derived from Landsat data acquired from 1984 to 2019 using our proposed approach for the atmospheric correction of Landsat data.

\begin{tabular}{cccccc}
\hline Month & $\begin{array}{c}\text { Mean T } \\
\text { Bracciano } \\
\left({ }^{\circ} \mathbf{C}\right)\end{array}$ & $\begin{array}{c}\text { St.D } \\
\text { Bracciano } \\
\left({ }^{\circ} \mathbf{C}\right)\end{array}$ & $\begin{array}{c}\text { Mean T } \\
\text { Martignano } \\
\left({ }^{\circ} \mathbf{C}\right)\end{array}$ & $\begin{array}{c}\text { St.D } \\
\text { Martignano } \\
\left({ }^{\circ} \mathbf{C}\right)\end{array}$ & $\begin{array}{c}\text { N. of } \\
\text { Measures }\end{array}$ \\
\hline January & 9.13 & 1.21 & 7.58 & 1.25 & 15 \\
February & 8.43 & 1.18 & 7.04 & 1.39 & 17 \\
March & 9.99 & 1.33 & 9.59 & 1.71 & 21 \\
April & 14.87 & 2.39 & 15.66 & 2.52 & 15 \\
May & 19.69 & 2.4 & 20.56 & 2.13 & 14 \\
June & 23.95 & 2.43 & 24.69 & 2.51 & 22 \\
July & 25.7 & 1.77 & 26.54 & 1.84 & 32 \\
August & 25.88 & 1.14 & 26.55 & 1.22 & 27 \\
September & 22.58 & 1.89 & 22.85 & 1.94 & 21 \\
October & 19.29 & 1.84 & 19.18 & 1.94 & 18 \\
November & 15.57 & 1.41 & 14.8 & 1.45 & 14 \\
December & 11.91 & 1.88 & 10.63 & 1.92 & \\
\hline Average & 17.25 & 1.74 & 17.14 & 1.82 & \\
\hline
\end{tabular}




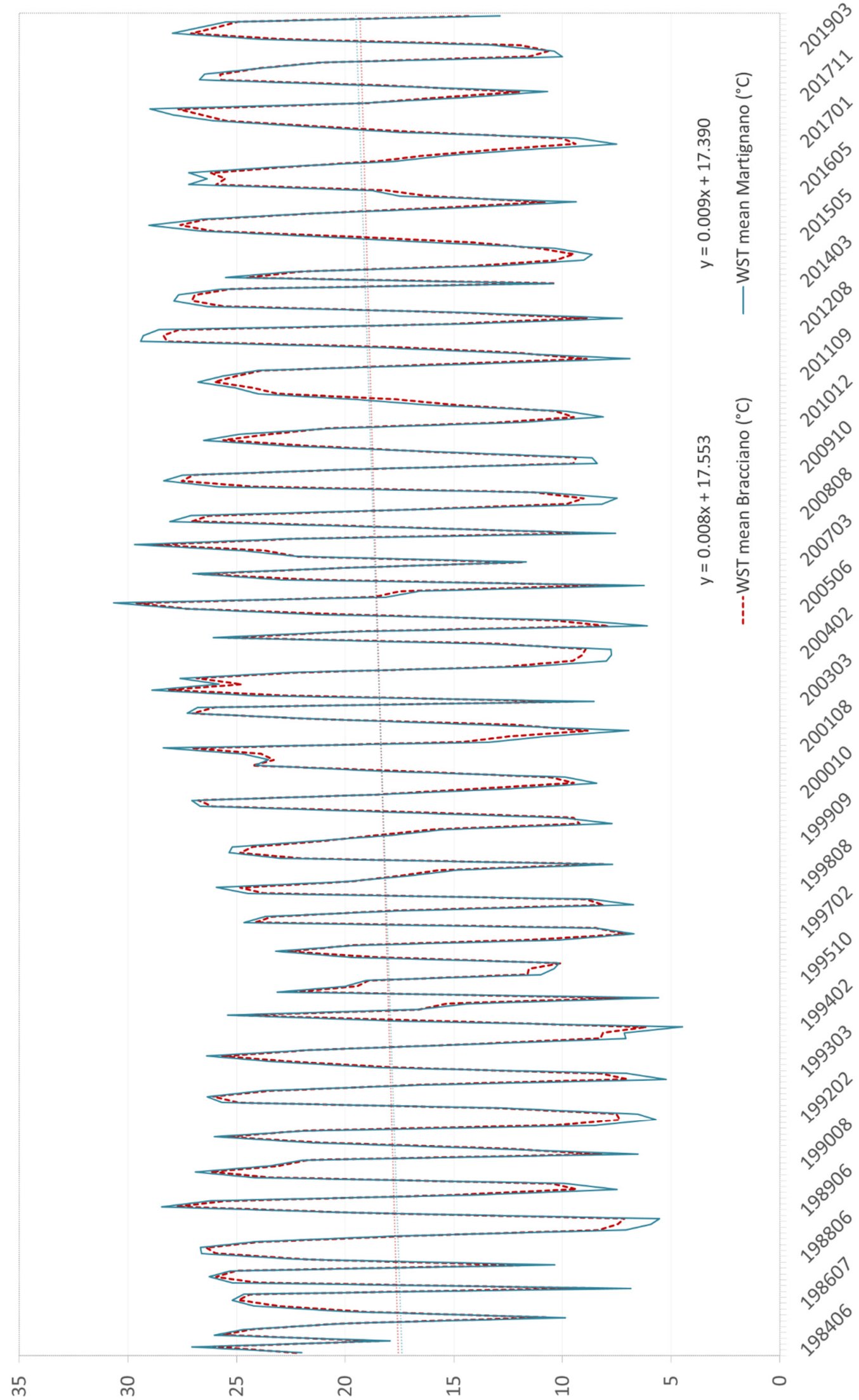

Figure 5. Monthly averaged WST derived from Landsat with a linear regression model for atmospheric correction products ("method 2") from 1984 to 2019 for Lake Bracciano (red) and Lake Martignano (light blue). 
The rise in water temperatures that can be observed in Figure 5 appears to be lighter than the one shown in Figure 3 for the period 2000-2019. To go deeper in the analysis of the dynamics of the WST long-term evolution, we split the initial time window into two subperiods of two decades. In particular, in Figure 6a we plot the water temperature values from 1984 to 2003, and the ones from 2000 to 2019 are reported in Figure 6b. The corresponding values, monthly averaged, are reported in Tables 7 and 8, respectively. We note that the WST shows a decreasing trend from 1984 to 2003, which is then inverted from 2000 to 2019. Globally, the sum of the two contributions produces a positive slope of WST temporal progress during the last 35 years for both lakes.

Table 7. Average year derived from Lansdat data acquired from 1984 to 2003 using our proposed approach for the atmospheric correction of Landsat data.

\begin{tabular}{cccccc}
\hline Month & $\begin{array}{c}\text { Mean T } \\
\text { Bracciano } \\
\left({ }^{\circ} \mathbf{C}\right)\end{array}$ & $\begin{array}{c}\text { St.D } \\
\text { Bracciano } \\
\left({ }^{\circ} \mathbf{C}\right)\end{array}$ & $\begin{array}{c}\text { Mean T } \\
\text { Martignano } \\
\left({ }^{\circ} \mathbf{C}\right)\end{array}$ & $\begin{array}{c}\text { St.D } \\
\text { Martignano } \\
\left({ }^{\circ} \mathbf{C}\right)\end{array}$ & $\begin{array}{c}\text { N. of } \\
\text { Measures }\end{array}$ \\
\hline January & 8.39 & 0.77 & 6.85 & 0.84 & 9 \\
February & 7.78 & 1.53 & 6.46 & 1.84 & 7 \\
March & 9.37 & 1.45 & 9.02 & 1.97 & 10 \\
April & 13.94 & 3.15 & 14.63 & 3.6 & 5 \\
May & 19.95 & 2.98 & 20.74 & 2.65 & 7 \\
June & 23.09 & 2.63 & 23.59 & 2.69 & 10 \\
July & 24.83 & 1.42 & 25.57 & 1.39 & 18 \\
August & 25.51 & 1.13 & 26.1 & 1.22 & 14 \\
September & 22.15 & 1.84 & 22.38 & 1.84 & 9 \\
October & 18.18 & 1.09 & 18.02 & 0.97 & 8 \\
November & 14.95 & 1.5 & 14.22 & 1.61 & 9 \\
December & 11.16 & 1.89 & 9.84 & 1.9 & \\
\hline Average & 16.61 & 1.78 & 16.45 & 1.88 & \\
\hline
\end{tabular}

Table 8. Average year derived from Lansdat data acquired from 2000 to 2019 using our proposed approach for the atmospheric correction of Landsat data.

\begin{tabular}{cccccc}
\hline Month & $\begin{array}{c}\text { Mean T } \\
\text { Bracciano } \\
\left({ }^{\circ} \mathbf{C}\right)\end{array}$ & $\begin{array}{c}\text { St.D } \\
\text { Bracciano } \\
\left({ }^{\circ} \mathbf{C}\right)\end{array}$ & $\begin{array}{c}\text { Mean T } \\
\text { Martignano } \\
\left({ }^{\circ} \mathbf{C}\right)\end{array}$ & $\begin{array}{c}\text { St.D } \\
\text { Martignano } \\
\left({ }^{\circ} \mathbf{C}\right)\end{array}$ & $\begin{array}{c}\text { N. of } \\
\text { Measures }\end{array}$ \\
\hline January & 9.96 & 0.87 & 8.43 & 0.99 & 8 \\
February & 9.05 & 0.71 & 7.67 & 1.041 & 12 \\
March & 10.54 & 1.05 & 10.22 & 1.56 & 14 \\
April & 15.65 & 1.89 & 16.53 & 1.83 & 12 \\
May & 20.44 & 2.33 & 21.24 & 2.06 & 10 \\
June & 24.97 & 2.18 & 25.8 & 2.12 & 15 \\
July & 26.45 & 1.61 & 27.39 & 1.65 & 18 \\
August & 26.39 & 0.98 & 27.16 & 1 & 16 \\
September & 23.17 & 1.77 & 23.48 & 1.88 & 10 \\
October & 20.22 & 1.78 & 20.13 & 2.01 & 8 \\
November & 16.07 & 1.06 & 15.19 & 1.25 & 8 \\
December & 13.16 & 0.79 & 11.9 & 0.84 & \\
\hline Average & 18.01 & 1.42 & 17.93 & 1.52 & \\
\hline
\end{tabular}




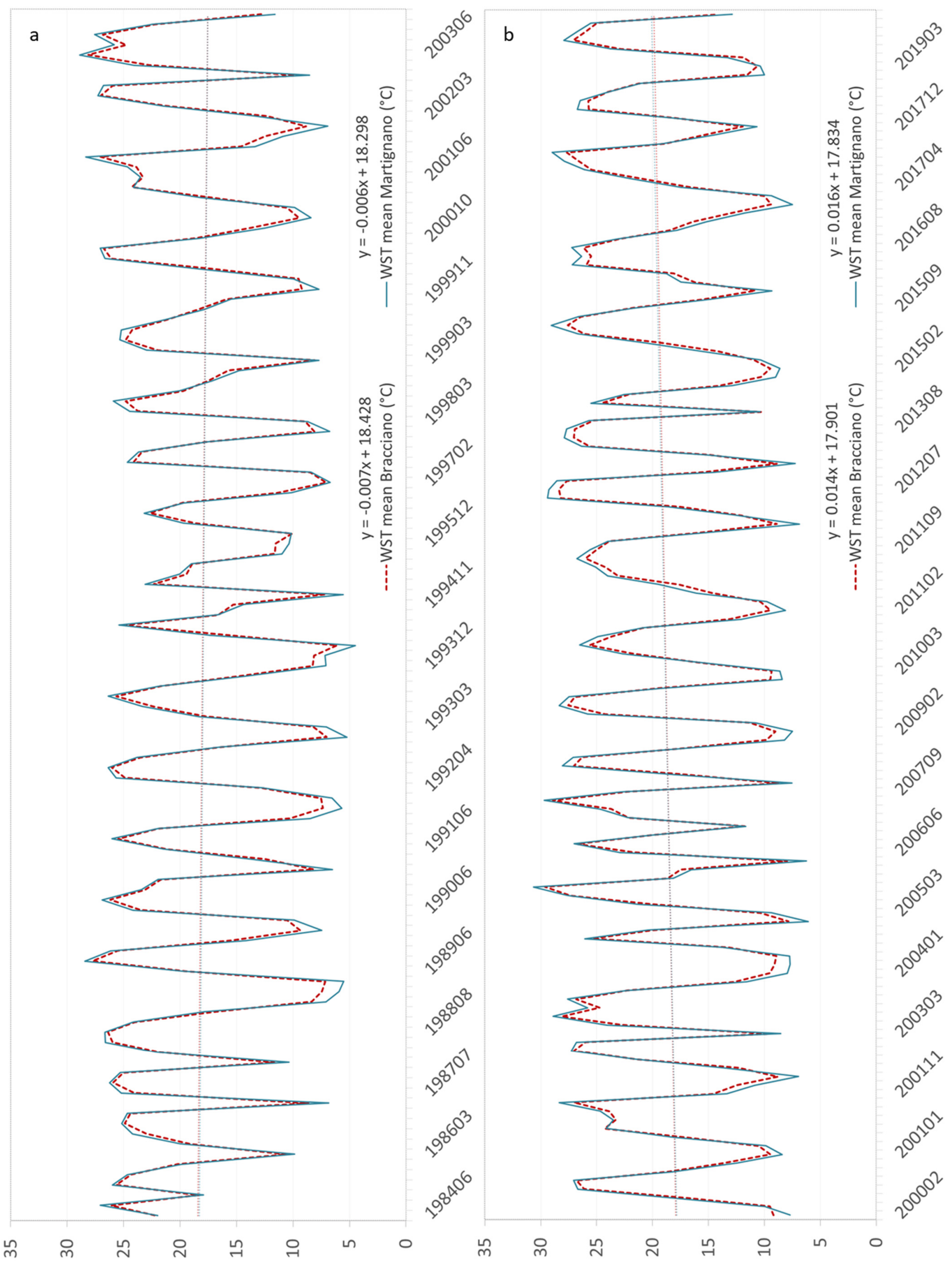

Figure 6. Split of Figure 5 considering two time intervals of two decades: from 1984 to 2003 (a) and from 2000 to 2019 (b). 
From the comparison between Tables 7 and 8, it is interesting to see that for both lakes in the time window 1984-2003, the mean WST values are a monthly average of at least $1^{\circ}$ degree Celsius lower than the corresponding periods during the decades 2000-2019. There are just a few exceptions: in May, the increase is "only" about $+0.49{ }^{\circ} \mathrm{C}$ for Lake Bracciano and $+0.51{ }^{\circ} \mathrm{C}$ for Lake Martignano; in August, the WST grew by $0.88{ }^{\circ} \mathrm{C}$ for Bracciano, while in November, water temperature increased by $0.97^{\circ} \mathrm{C}$ for Martignano.

In agreement with the results presented in the previous section, it was confirmed that Lake Martignano's WST is warming faster than that of Lake Bracciano. In fact, the mean water temperature of the latter increased by $1.40{ }^{\circ} \mathrm{C}$ (from $16.61{ }^{\circ} \mathrm{C}$ to $18.01{ }^{\circ} \mathrm{C}$ ) while the former WST increased by $1.48^{\circ} \mathrm{C}$ (from $16.45^{\circ} \mathrm{C}$ to $17.93{ }^{\circ} \mathrm{C}$ ).

In order to evaluate the difference between the temperature values obtained through the use of "method 1" and those derived from the usage of linear regression for atmospheric correction ("method 2"), we compared the WST estimates computed with the two methods for both lakes using the same Landsat data considered in Section 4.2. The resulting scatter plots are shown in Figure 7. It can be seen that, when comparing the two datasets generated from the same Landsat products, noticeable similarities between the two test sites are evident. In particular, we obtained an $\mathrm{R}^{2}$ of about 0.99 either way, and $\mathrm{RMSE}=0.68^{\circ} \mathrm{C}$ for Lake Bracciano and $\mathrm{RMSE}=0.71^{\circ} \mathrm{C}$ for Lake Martignano.
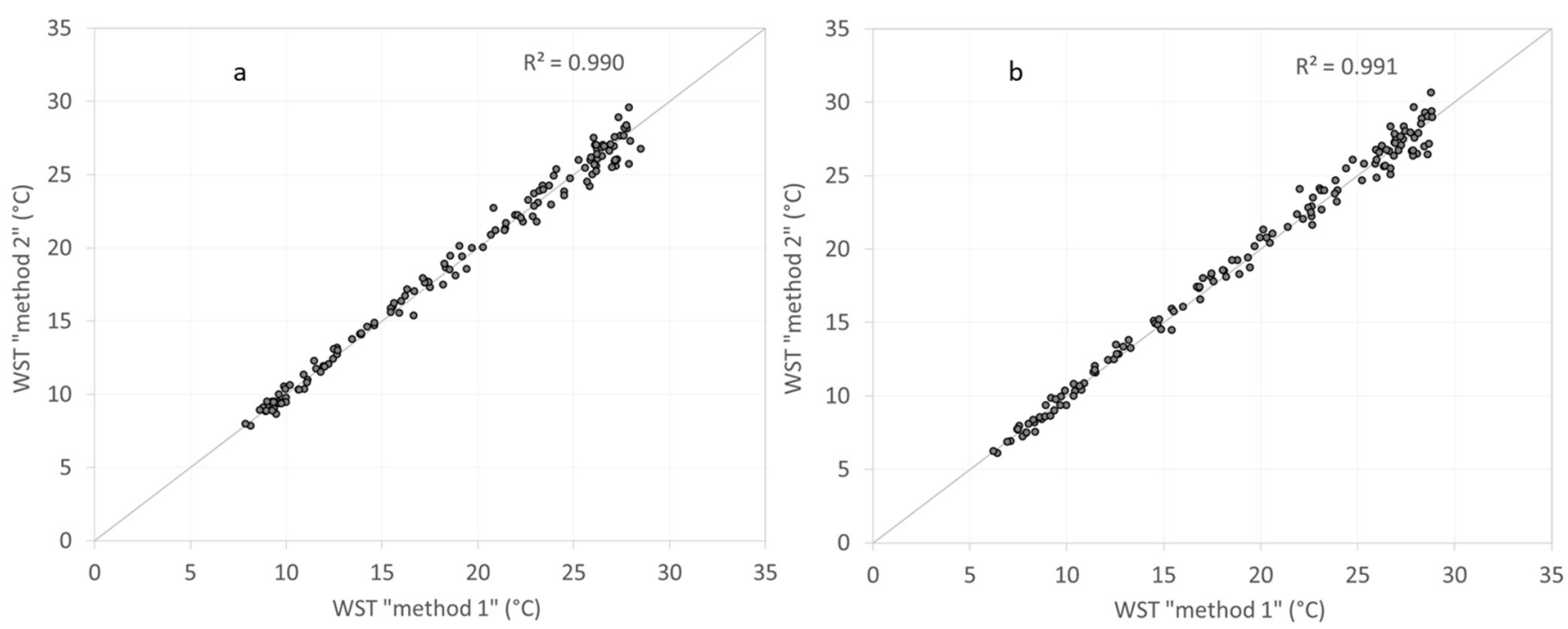

Figure 7. Water surface temperatures for Lake Bracciano (a) and Lake Martignano (b) derived from the same Landsat products acquired from 2000 to 2019 using the proposed standard algorithm (the "method 1" defined in Section 3.1) and the regression lines (the "method 2" defined in Section 3.2) for the atmospheric correction of the images.

\section{Discussion}

A general rising trend in water surface temperatures during the last few decades was retrieved for the test sites considered. The analysis with the two proposed approaches showed that Lake Martignano's surface has been warming faster than that of Lake Bracciano. This result is in agreement with our expectations due to the geomorphological differences between the water bodies that lead Martignano's water surface temperature to warm faster than that of Lake Bracciano. Furthermore, the greater the thermal capacity, the slower the water body tends to change its temperature. We observed (Figure 3) that the maximum values of water surface temperature in summer were registered for Lake Martignano as well as the minimum ones during winter, which is consistent with the previous statement. For some spring and autumn months we noted a higher standard deviation. A possible explanation of larger standard deviation values could be that specific periods of the year may be more affected by climate change than others, leading to a more evident increase in 
lake WST values during the last few decades in those periods, as was also reported for the USA's Great Lakes [28].

According to what was observed during the periods 2000-2019 and 1984-2019 with the proposed linear regression approach, a positive trend in WST evolution was obtained. Nevertheless, by splitting the dataset into two temporal windows of two decades, the analysis revealed that, from 1984 to 2003, the WST of both lakes was slightly decreasing. From 2000 to 2019, on the contrary, both lakes show an increasing trend of temperature values. As previously explained (Sections 3.1 and 3.2), atmospheric calibration obtained using the NASA atmospheric correction parameter calculator is addressed with "method 1" while atmospheric calibration derived through regression lines is referred with "method 2". Comparing the two approaches, a slightly less steep slope was noted using "method 2".

From a linear regression applied to the monthly averaged WST distribution, we derived a yearly warming trend of about $+0.12{ }^{\circ} \mathrm{C} / \mathrm{y}$ for Lake Bracciano and about $+0.14{ }^{\circ} \mathrm{C} / \mathrm{y}$ for Lake Martignano through "method 1" from 2000 to 2019. For the same period, by applying the proposed "method 2", the WST increase has been of about $+0.10^{\circ} \mathrm{C} / \mathrm{y}$ for Lake Bracciano and about $+0.11^{\circ} \mathrm{C} / \mathrm{y}$ for Lake Martignano. The presented trends are higher compared to the ones reported in a similar study for Sardinia's lakes from 2000 to 2018 [18], probably due to differences in the satellite products that were considered (mainly MODIS vs. Landsat) and to the approach that was used for performing the analysis. On the other hand, the computed growth rates are highly consistent with those reported for the period 1993-2016 in another work about sea surface temperature trends in the Mediterranean [29]. Moreover, by exploiting the proposed "method 2", we were able to extend the analysis back to 1984. A yearly water temperature increase of about $+0.05^{\circ} \mathrm{C} / \mathrm{y}$ for Lake Bracciano and about $+0.06^{\circ} \mathrm{C} / \mathrm{y}$ for Lake Martignano from 1984-2019 was retrieved. By comparing these growth rates with the ones that we derived with the same approach for the period 2000-2019, as previously reported, a rise in WST of about $+0.10^{\circ} \mathrm{C} / \mathrm{y}$ (2.04 factor) for Lake Bracciano and about $+0.11^{\circ} \mathrm{C} / \mathrm{y}$ (1.95 factor) for Lake Martignano emerges. This result suggests that, in the last 20 years, the WST increase has doubled with respect to the last 35 years for the considered water bodies.

\subsection{Validation}

\subsubsection{In-Situ Data Used for Validation}

One approach to evaluate the results' accuracy consisted of comparing the temperature values obtained with the proposed standard algorithm with in-situ measurements. Since ground-based WST values for both Lake Bracciano and Lake Martignano were not available, on seven occasions we physically measured the water temperature on Lake Bracciano's surface simultaneously to the Landsat acquisition over the study area. The on-site temperature measurement was carried out using the Habor HBCP022AH probe thermometer, maintaining a stable depth of about $5 \mathrm{~cm}$ whilst registering the temperature.

To extend the in situ validation dataset, we exploited the WST values registered from some buoys located on the surface of five lakes in the United States, which are provided by NOAA at the web page https:/ / www.ndbc.noaa.gov/ (accessed on 7 May 2021). We collected and processed through "method 1" a total of 100 clear sky Landsat products registered over the selected US lakes selected. The details of the in situ validation dataset are summarized in Table 9. The selected USA validation sites are all located in a range between $35^{\circ} \mathrm{N}$ and $46^{\circ} \mathrm{N}$ latitude, in which our Italian test sites are also located, in order to maintain as strong a comparison as possible. Furthermore, each buoy is able to register the water temperature every $10 \mathrm{~min}$, providing a comparison as close as possible to the corresponding Landsat acquisition. 
Table 9. Summary of the in situ data considered for validating the WST obtained with the proposed standard algorithm.

\begin{tabular}{cccccc}
\hline Lake & Latitude & Longitude & N. of Data & Year & Satellite \\
\hline Bracciano & $42.12 \mathrm{~N}$ & $12.23 \mathrm{E}$ & 7 & 2017 & Landsat-7/-8 \\
Huron & $45.35 \mathrm{~N}$ & $-82.84 \mathrm{~W}$ & 9 & $2009-2016$ & Landsat-5/-7/-8 \\
Michigan & $42.67 \mathrm{~N}$ & $-87.03 \mathrm{~W}$ & 21 & $2009-2017$ & Landsat-5/-7/-8 \\
Ontario & $43.62 \mathrm{~N}$ & $-77.41 \mathrm{~W}$ & 39 & $2009-2017$ & Landsat-5/-7/-8 \\
Mohave & $35.46 \mathrm{~N}$ & $-114.67 \mathrm{~W}$ & 15 & $2016-2017$ & Landsat-7/-8 \\
Mead & $36.13 \mathrm{~N}$ & $-114.41 \mathrm{~W}$ & 16 & $2016-2017$ & Landsat-7/-8 \\
\hline
\end{tabular}

Figure 8 shows a scatter plot generated by combining the in situ data and the water surface temperature values retrieved from the corresponding Landsat acquisitions applying the standard algorithm shown in Section 3.1. Red dots are associated to the measurements physically taken from Lake Bracciano's surface.

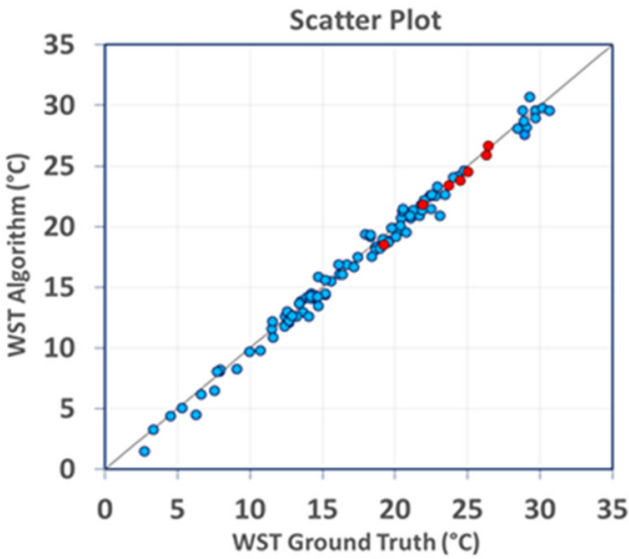

\begin{tabular}{|ccc|}
\hline $\mathbf{\Sigma}$ Test Data & $\mathbf{R M S E}\left({ }^{\circ} \mathbf{C}\right)$ & $\mathbf{R Q}$ \\
\hline 107 & 0.651 & 0.9907 \\
\hline
\end{tabular}

Figure 8. Scatter plot from the algorithm validation phase. Summary of the algorithm validation with root mean square error (RMSE), Pearson square coefficient (RQ) and the number of test data.

The value of 0.99 related to the R-squared coefficient indicates a significant correlation between the two WST datasets compared, confirming the reliability of our results. Note that previous studies reported that the variability in spatial and temporal atmospheric correction parameters in a single-band LST algorithm could generate an RMSE up to $\pm 2{ }^{\circ} \mathrm{C}[30,31]$. During the summer, high temperatures can lead to a higher bias between in situ measurements and those retrieved from satellite data. This is probably due to the uncertain increase in the atmospheric correction parameters estimation [32,33]. Note that the NASA web tool (see Section 3.1) used allows us to minimize the discrepancy between the satellite's time of acquisition and the time at which the atmospheric parameters necessary for the calibration are computed.

\subsubsection{Sentinel-3/SLSTR WST Data Used for Validation}

To show another point of view for the assessment of our results, we studied the comparison between the WST derived from cloud-free Landsat-7 and Landsat- 8 products with Sentinel-3 SLSTR Level-2 WST products of the same day from 2016 (launch year of the Sentinel-3A mission) to 2019. This analysis was only carried out for Lake Bracciano, since the small dimensions of Lake Martignano makes it unsuitable for the use of $1 \mathrm{~km}$ spatial resolution images, which is proper of SLSTR products. Only night Sentinel-3 data, which are available with higher frequency over the considered area, with a cloud probability less than 0.5 on average over Lake Bracciano were selected for the described comparison. SLSTR Level-2 WST products are freely available at Eumetsat CODA repository (https: / / coda.eumetsat.int/\#/home, accessed on 8 September 2021) or through one of the 
Copernicus Data and Information Access Service (DIAS) accessible at link https: / www. copernicus.eu/en/access-data/dias (accessed on 7 May 2021). Detailed information about the Sentinel-3 Level-2 WST product is available at https: / sentinel.esa.int/web/sentinel/ user-guides/sentinel-3-slstr/product-types/level-2-wst (accessed on 7 May 2021). The summary of the considered Landsat and Sentinel-3 products is reported in Table 10, while Figure 9 shows the two obtained WST time series.

Table 10. Summary of characteristics of the dataset for comparing WST derived from Landsat and Sentinel-3 data from 2016 to 2019.

\begin{tabular}{ccc}
\hline Satellite & N. of Images & Spatial Res. $(\mathbf{m})$ \\
\hline Sentinel-3/SLSTR & 30 & 1000 \\
Landsat-7/ETM+ & 13 & 60 \\
Landsat-8/TIRS & 17 & 100 \\
\hline
\end{tabular}

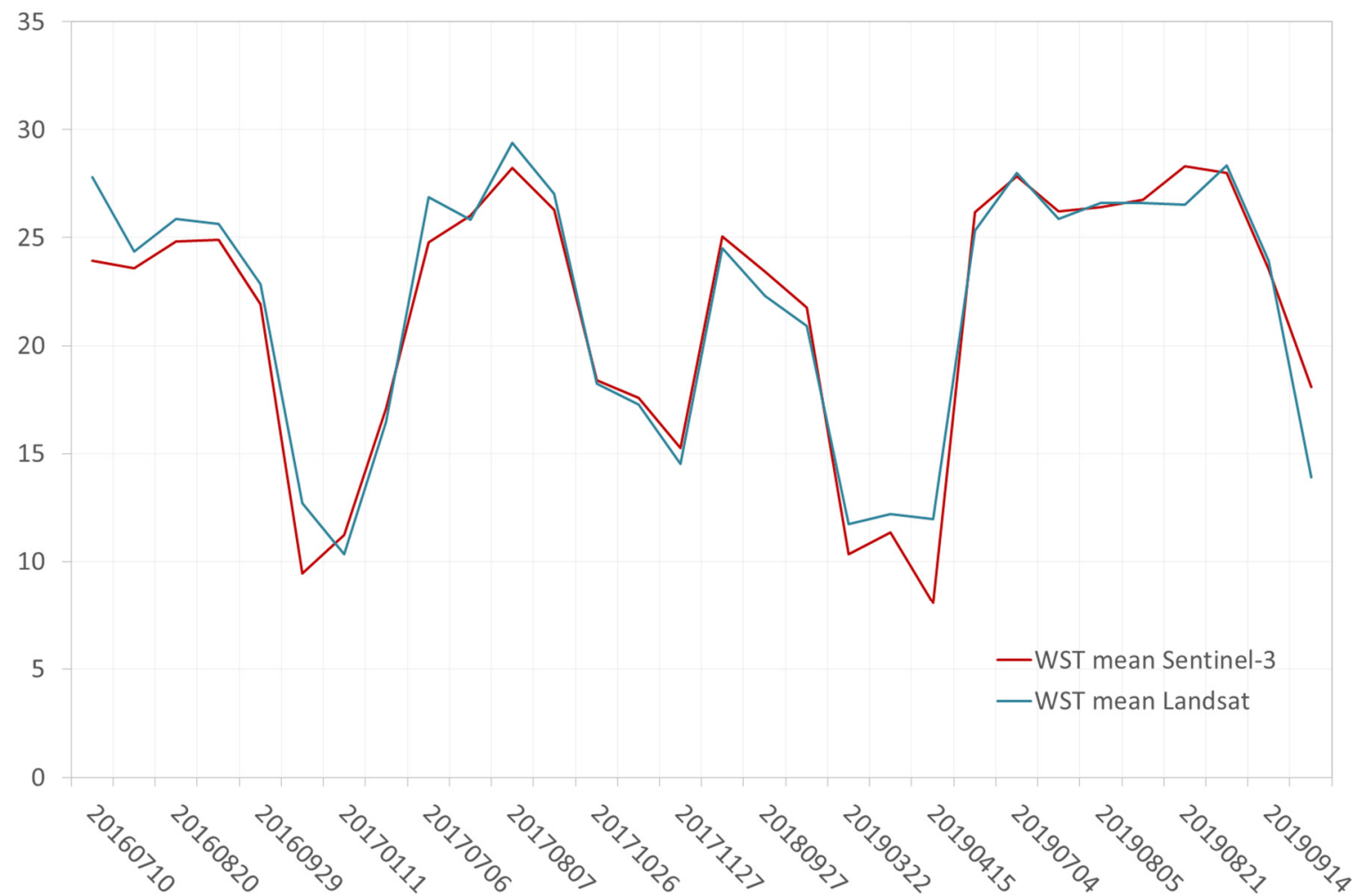

Figure 9. Comparison between the WST derived from Landsat and Sentinel-3 SLSTR Level-2 WST products of the same day.

We found a high correlation when comparing the 2016-2019 water surface temperatures for Lake Bracciano which were retrieved from the Landsat-7 and Landsat-8 images using the proposed "method 1" and those which were retrieved by the Sentinel-3 SLSTR products on the same days $\left(R^{2}=0.93\right)$. It should be noted that WST evolution derived with Planck's simplified approach is in agreement with SLSTR, despite the two sensors having different acquisition times (about $11 \mathrm{~h}$ constantly shifted for the considered products); furthermore we obtained a root-mean-square deviation between the two values distribution of $1.63{ }^{\circ} \mathrm{C}$.

\section{Conclusions}

Lake ecosystems could be one of the most impacted by climate change due to the effects that droughts, rising temperatures, changes in atmospheric composition and other climatic variables can generate on lake chemical-physical characteristics. Especially for 
large water bodies, several ground-based networks of measurements were set up for monitoring the evolution of critical lake parameters, such as the water temperature. At the same time, the huge amount of information provided by satellite data over time can significantly integrate the information collected in situ. Anyway, for small-medium size lakes around the world, there is still a gap of analysis to fill in through ad hoc studies, in particular using long-term data time series.

In this work, the water surface temperatures monitored for two water bodies in central Italy using satellite data during the last few was presented. Almost 500 Landsat products were collected in a dataset covering the period 1984-2019. From visual inspection, 191 and 172 clear sky products for 1984-1999 and 2000-2019, respectively, were selected and, to optimize the accuracy of the results, the analysis was carried out by taking into account only abstracted products. A novel linear regression-based approach for atmospheric calibration of Landsat thermal data before 2000 was proposed. The comparison with the validated standard algorithm showed that results were in agreement $\left(\mathrm{R}^{2}=0.99\right)$ with $\mathrm{RMSE}$ of about $0.7^{\circ} \mathrm{C}$.

Since 1984, the computed WST time series shows a general rising trend in water surface temperatures, in accordance with the current global warming era, for both of the test cases considered. Furthermore, the results of the study highlighted how a smaller and shallower water body is suffering more from the impacts of climate change. In particular, from 2000 to 2019, by applying a simplified Planck's equation-based algorithm with two different methods for estimating the BOA spectral radiance the WST for Lake Bracciano has increased by about $+0.11^{\circ} \mathrm{C} / \mathrm{y}$ on average, whilst for Lake Martignano the WST growth rate has been about $+0.13^{\circ} \mathrm{C} / \mathrm{y}$ on average.

Moreover, a significant outcome of the research using the proposed "method 2 " is that, from 2000 to 2019, compared to what can be retrieved from 1984 to 2019, the water of both the lakes considered is warming twice as fast.

The resulting water surface temperature estimates were highly consistent with insitu data, and the comparison between the WST values obtained using the proposed methodology with Sentinel-3 SLSTR Level 2 products of the same date shown significant similarities during in clear-sky conditions over the test sites.

In the future, the same approach proposed in this paper might be replicated to other medium-sized lakes in the Mediterranean area; moreover, the daily acquisition of Sentinel-3 data will permit a more detailed analysis over time.

Author Contributions: Conceptualization, D.D.S.; methodology, D.D.S. and F.D.F.; software, D.D.S.; validation, D.D.S., F.D.F. and G.S.; formal analysis, D.D.S., F.D.F. and G.S.; investigation, D.D.S.; resources, D.D.S., F.D.F. and G.S.; data curation, D.D.S.; writing-original draft preparation, D.D.S. and F.D.F.; writing-review and editing, F.D.F. and G.S.; visualization, F.D.F.; supervision, F.D.F. and G.S.; project administration, F.D.F. and G.S.; funding acquisition, F.D.F. and G.S. All authors have read and agreed to the published version of the manuscript.

Funding: This research received no external funding.

Data Availability Statement: Not applicable.

Conflicts of Interest: The authors declare no conflict of interest.

\section{References}

1. Jeppesen, E.; Meerhoff, M.; Davidson, T.; Trolle, D.; Søndergaard, M.; Lauridsen, T.; Beklioglu, M.; Brucet, S.; Volta, P.; GonzálezBergonzoni, I.; et al. Climate change impacts on lakes: An integrated ecological perspective based on a multi-faceted approach, with special focus on shallow lakes. J. Limnol. 2014, 73, 88-111. [CrossRef]

2. Kosten, S.; Huszar, V.L.M.; Bécares, E.; Costa, L.S.; van Donk, E.; Hansson, L.-A.; Jeppesen, E.; Kruk, C.; Lacerot, G.; Mazzeo, N.; et al. Warmer climates boost cyanobacterial dominance in shallow lakes. Glob. Chang. Biol. 2012, 18, 118-126. [CrossRef]

3. Intergovernmental Panel on Climate Change (IPCC). Climate Change 2014: Synthesis Report. Contribution of Working Groups I, II and III to the Fifth Assessment Report of the Intergovernmental Panel on Climate Change; Pachauri, R.K., Meyer, L.A., Eds.; IPCC: Geneva, Switzerland, 2015; p. 151. 
4. Ambrosetti, W.; Barbanti, L. Deep water warming in lakes: An indicator of climatic change. J. Limnol. 1999, 58, 1-9. [CrossRef]

5. Livingstone, D.M. Impact of Secular Climate Change on the Thermal Structure of a Large Temperate Central European Lake. Clim. Chang. 2003, 57, 205-225. [CrossRef]

6. Adrian, R.; O’Reilly, C.M.; Zagarese, H.; Baines, S.B.; Hessen, D.O.; Keller, W.; Livingstone, D.M.; Sommaruga, R.; Straile, D.; van Donk, E.; et al. Lakes as sentinels of climate change. Limnol. Oceanogr. 2009, 54, 2283-2297. [CrossRef] [PubMed]

7. Schneider, P.; Hook, S.J.; Radocinski, R.G.; Corlett, G.K.; Hulley, G.C.; Schladow, S.G.; Searsburg, T.E. Satellite observations indicate rapid warming trend for lakes in California and Nevada. Geophys. Res. Lett. 2009, 36, L22402. [CrossRef]

8. Schneider, P.; Hook, S.J. Space observations of inland water bodies show rapid surface warming since 1985. Geophys. Res. Lett. 2010, 37, L22405. [CrossRef]

9. O'Reilly, C.M.; Sharma, S.; Gray, D.K.; Hampton, S.E.; Read, J.S.; Rowley, R.J.; Schneider, P.; Lenters, J.D.; McIntyre, P.B.; Kraemer, B.M.; et al. Rapid and highly variable warming of lake surface waters around the globe. Geophys. Res. Lett. 2015, 42, 10773-10781. [CrossRef]

10. Winslow, L.A.; Leach, T.H.; Rose, K.C. Global lake response to the recent warming hiatus. Environ. Res. Lett. $2018,13,054005$. [CrossRef]

11. Havens, K.; Jeppesen, E. Ecological Responses of Lakes to Climate Change. Water 2018, 10, 917. [CrossRef]

12. Kraemer, B.M.; Mehner, T.; Adrian, R. Reconciling the opposing effects of warming on phytoplankton biomass in 188 large lakes. Sci. Rep. 2017, 7, 10762. [CrossRef] [PubMed]

13. Niedrist, G.H.; Psenner, R.; Sommaruga, R. Climate warming increases vertical and seasonal water temperature differences and inter-annual variability in a mountain lake. Clim. Chang. 2018, 151, 473-490. [CrossRef]

14. Woolway, R.I.; Jennings, E.; Shatwell, T.; Golub, M.; Pierson, D.C.; Maberly, S.C. Lake heatwaves under climate change. Nat. Cell Biol. 2021, 589, 402-407. [CrossRef] [PubMed]

15. Sharma, S.; Gray, D.K.; Read, J.S.; O’Reilly, C.M.; Schneider, P.; Qudrat, A.; Gries, C.; Stefanoff, S.; Hampton, S.E.; Hook, S.; et al. A global database of lake surface temperatures collected by in situ and satellite methods from 1985-2009. Sci. Data 2015, 2, 150008. [CrossRef]

16. Wan, W.; Limin, Z.; Xie, H.; Hongjie, X.; Long, D.; Zhao, L.; Han, Z.; Cui, Y.; Liu, B.; Wang, C.; et al. A comprehensive data set of lake surface water temperature over the Tibetan Plateau derived from MODIS LST products 2001-2015. Sci. Data 2017, 4, 170095. [CrossRef]

17. Pareeth, S.; Bresciani, M.; Buzzi, F.; Leoni, B.; Lepori, F.; Ludovisi, A.; Morabito, G.; Adrian, R.; Neteler, M.; Salmaso, N. Warming trends of perialpine lakes from homogenised time series of historical satellite and in-situ data. Sci. Total Environ. 2017, 578, 417-426. [CrossRef] [PubMed]

18. Virdis, S.G.P.; Soodcharoen, N.; Lugliè, A.; Padedda, B.M. Estimation of satellite-derived lake water surface temperatures in the western Mediterranean: Integrating multi-source, multi-resolution imagery and a long-term field dataset using a time series approach. Sci. Total Environ. 2020, 707, 135567. [CrossRef] [PubMed]

19. Taviani, S.; Henriksen, H.J. The application of a groundwater/surface-water model to test the vulnerability of Bracciano Lake (near Rome, Italy) to climatic and water-use stresses. Hydrogeol. J. 2015, 23, 1481-1498. [CrossRef]

20. Management Plan and Preservation Actions for the "Bracciano-Martignano" area (ZPS IT6030085) and Annex Sites Management. 2009. Available online: https://www.provincia.vt.it/Ambiente/natura2000/bracciano/PdGBracciano.pdf (accessed on 30 August 2020).

21. Azzella, M.M.; Ricotta, C.; Blasi, C. Aquatic macrophyte diversity assessment: Validation of a new sampling method for circular-shaped lakes. Limnol. Ecol. Manag. Inland Waters 2013, 43, 492-499. [CrossRef]

22. Troia, A.; Azzella, M.M. Isoëtes sabatina (Isoëtaceae Lycopodiophyta), a new aquatic species from central Italy. Plant Biosyst. Int. J. Deal. All Asp. Plant Biol. 2013, 147, 1052-1058. [CrossRef]

23. Butcher, J.B.; Nover, D.; Johnson, T.E.; Clark, C.M. Sensitivity of lake thermal and mixing dynamics to climate change. Clim. Chang. 2015, 129, 295-305. [CrossRef]

24. Yu, X.; Guo, X.; Wu, Z. Land Surface Temperature Retrieval from Landsat 8 TIRS-Comparison between Radiative Transfer Equation-Based Method, Split Window Algorithm and Single Channel Method. Remote Sens. 2014, 6, 9829-9852. [CrossRef]

25. Barsi, J.A.; Barker, J.L.; Schott, J.R. An Atmospheric Correction Parameter Calculator for a single thermal band earth-sensing instrument. In Proceedings of the 2003 IEEE International Geoscience and Remote Sensing Symposium, Toulouse, France, 21-25 July 2003; Volume 5, pp. 3014-3016.

26. Barsi, J.A.; Schott, J.R.; Palluconi, F.D.; Hook, S.J. Validation of a web-based atmospheric correction tool for single thermal band instruments. In Proceedings of the Earth Observing Systems X, San Diego, CA, USA, 22 August 2005; Volume 5882, pp. 136-142. [CrossRef]

27. Davies, J.A.; Robinson, P.J.; Nunez, M. Field Determinations of Surface Emissivity and Temperature for Lake Ontario. J. Appl. Meteorol. Clim. 1971, 10, 811-819. [CrossRef]

28. Climate Change Indicators in the United States: Great Lakes Water Levels and Temperatures. 2016. Available online: https: / / www.epa.gov / climate-indicators (accessed on 3 November 2021).

29. Pastor, F.; Valiente, J.A.; Palau, J.L. Sea Surface Temperature in the Mediterranean: Trends and Spatial Patterns (1982-2016). Pure Appl. Geophys. 2018, 175, 4017-4029. [CrossRef] 
30. Kelly, G.; Laraby, J.; Schott, R. Uncertainty estimation method and Landsat 7 global validation for the Landsat surface temperature product. Remote Sens. Environ. 2018, 216, 472-481. [CrossRef]

31. Tardy, B.; Rivalland, V.; Huc, M.; Hagolle, O.; Marcq, S.; Boulet, G. A Software Tool for Atmospheric Correction and Surface Temperature Estimation of Landsat Infrared Thermal Data. Remote Sens. 2016, 8, 696. [CrossRef]

32. Prats, J.; Reynaud, N.; Rebière, D.; Peroux, T.; Tormos, T.; Danis, P.-A. LakeSST: Lake Skin Surface Temperature in French inland water bodies for 1999-2016 from Landsat archives. Earth Syst. Sci. Data 2018, 10, 727-743. [CrossRef]

33. Malakar, N.K.; Hulley, G.C.; Hook, S.J.; Laraby, K.; Cook, M.; Schott, J.R. An Operational Land Surface Temperature Product for Landsat Thermal Data: Methodology and Validation. IEEE Trans. Geosci. Remote Sens. 2018, 56, 5717-5735. [CrossRef] 